\title{
Why was Introduction of Station Blackout Regulation Late?
}

\section{-Failure to Apply Knowledge of Possible Major Tsunamis to Protect the Fukushima Daiichi Nuclear Power Plant-}

\author{
Former employee of the Japan Atomic Energy Research Institute, \\ Yasuhiko Miyasaka
}

\begin{abstract}
The severe accidents that occurred at the Fukushima Daiichi Nuclear Power Plant, which is operated by the Tokyo Electric Power Company (TEPCO), warrant a thorough examination and validation of factors such as the response and applicable regulations. To begin with, what were the reasons behind the belated regulation of station blackouts (SBOs) at nuclear power plants? Why did seismic regulations not reflect the possibility of earthquakes and tsunamis adequately despite the earlier warnings from experts? In Japan, seismic measures for safeguarding nuclear facilities were introduced in earnest a few years after the Great Hanshin Earthquake of 1995. A major revision of the Regulatory Guide for Reviewing the Seismic Design of Nuclear Power Reactor Facilities was announced in September 2006 in the wake of another major earthquake in Niigata. Regrettably, this revision took too long. It is high time Japan restructured its regulatory system giving due consideration to the importance of safety-related research. An independent agency is postulated as a part of this restructuring. However, the first step must be to examine the earthquake responses taken to date.

This commentary has been written with reference to the flood-induced loss of external power supplies, the tsunami-induced loss of cooling pump functionality, and other events that offer important lessons. It also presents the state of severe accident regulations in the United States and France before providing recommendations for the regulatory measures to be taken in Japan.
\end{abstract}

\section{Events that Teach Important Lessons}

The Blayais Nuclear Power Plant experienced a shutdown of its four pressurized water reactors (PWR; 900 MWe $\times 4$ units) when it lost a $225 \mathrm{kV}$ external power supply at 7:30 pm. on December 27, 1999. Units 2 and 4 also lost their $400 \mathrm{kV}$ power supply lines, but they were replaced by emergency diesel generators to supply power. Units 1 and 2 were flooded when the tide wall facing the Gironde River (designed to withstand a water level rise of up to $5 \mathrm{~m}$ ) was overwhelmed by a combination of the incoming tide and exceptionally high winds. The

DOI : 10.15669/fukushimainsights.Vol.1.177

(C) 2021 Atomic Energy Society of Japan. All rights reserved.

Originally published in Journal of the Atomic Energy Society of Japan (ISSN 1882-2606), Vol. 54, No. 1, p. 32-35 (2012) in

Japanese. (Japanese version accepted: October 28, 2011) 
submersion of the pumps and power distribution equipment led to functional losses of the safety systems and the cooling systems. However, the resultant power plant emergency was resolved owing to the cooling of the reactor cores with steam generators, the recovery of the essential service water system (ESWS) in the afternoon of December 30, and the successful resumption of the operation of Unit 4 to supply power in the early morning of December 30 after its warm shutdown. Unit 3, which was affected immediately after its fuel had been replaced, could not be operated due to problems experienced during an attempted restart after due preparations had been made ${ }^{1,2)}$.

On December 26, 2004, Unit 2 of the Madras Nuclear Power Plant (PHWR; 200 MWe) in India experienced a shutdown due to external flooding when the tsunami triggered by the Indian Ocean Earthquake (M 9.1) submerged the motor for the essential process pump in the pump house ${ }^{3)}$.

Such events are rarely mentioned in journals of the nuclear energy-related societies in Japan, reports, and other materials, which raises questions concerning the seriousness of subsequent surveys and discussions to learn from them. Obviously, demonstration tests cannot be conducted with respect to station blackouts (SBOs), so it is vital for on-site engineers to learn from near SBO events experienced at actual power plants. The regulatory authorities and utilities must become able to detect important information on such events and respond to it.

\section{Severe Accident Regulations and Measures Taken in the United States and France}

After the accident that occurred at Three Mile Island (TMI)-2 in March 1979, the United States experienced four short-term SBO events ${ }^{4)}$ from 1984 to 1990, as shown in Table 1. According to regulatory guidelines enacted in 2003 entitled NUREG-1776 ${ }^{5}$, the country has experienced four near SBO events up to 1998 due to disasters such as hurricanes and tornadoes.

In response to these events, SBO regulations were discussed as an urgent matter. The resultant regulations, which were close to being finalized in 2003, require an ability to withstand including long-term SBOs and restore external power supplies.

In accordance with the Mark I Containment Long-Term Program Safety Evaluation Report (July 1980), NUREG-0661 required the installation of pressure-tight venting systems. Later, the NRC established Rule 10 CFR 50.63 "Loss of all alternating current power" (July 1988) and Regulatory Guide (RG) 1.155 "Station Blackout" (August 1988). In the same year, the power utilities and plant manufacturers jointly established NUMARC-8700, which stipulates more detailed evaluation methods than RG 1.155 does. The NRC has approved this private standard.

Mark-I analysis results based on an analysis code (MELCOR) have also been reported with regard to the escalation of a severe accident that was caused by a long-term SBO (NUREG/ CR-5850; May 1994). The assigned condition for Peach Bottom 2 (MARK-I; ca. 3,300 MWt) was cooling for only 6 hours with batteries after the reactor shutdown and subsequent SBO and the failure of the emergency cooling system. According to this analysis, the water level in the reactor core dropped to the tops of the fuel region in about 15 to 17 hours. Approximately 120 minutes later, a core meltdown began and then escalated into a core collapse and damage to the reactor pressure vessel ${ }^{6)}$.

In France, the SBO regulations were tightened in 1977 because the policy target of restricting the possibility of events with an unacceptable impact to $10^{-6}$ per year was deemed 
Table 1 Examples of SBO and near SBO events experienced in the United States up to the 1990s ${ }^{4,5)}$

\begin{tabular}{|c|c|c|}
\hline Date occurred & Plant Name & Overview of SBO or near SBO events \\
\hline July 26, 1984 & $\begin{array}{l}\text { Susquehanna } 2 \\
\text { (BWR; } 1,140 \mathrm{MWe})\end{array}$ & $\begin{array}{l}\text { Short-term SBO event: Four emergency diesel generators (EDGs) failed to start up for } \\
17 \text { minutes during a simulated loss of external power supplies in a test operation with an } \\
\text { output of } 30 \% \text {. Cause: Operational mistake by an operator. }\end{array}$ \\
\hline November 20,1985 & $\begin{array}{l}\text { San Onofre } 1 \\
\text { (PWR; } 450 \mathrm{MWe})\end{array}$ & $\begin{array}{l}\text { Short-term SBO event: A condenser was under repair due to a seawater leakage while } \\
\text { the plant was operating at an output of } 60 \% \text {. After a connection to an external power } \\
\text { supply was established, a grounding fault alarm was issued for a safety bus leading } \\
\text { from an auxiliary transformer. The power supply from the bus was lost after various } \\
\text { procedures had been conducted to investigate the cause. This loss resulted in a short- } \\
\text { term SBO event. The external power supply was restored in } 4 \text { minutes despite four } \\
\text { failed attempts being made due to a failure to remember to press the reset button. }\end{array}$ \\
\hline February 20, 1990 & $\begin{array}{l}\text { Alvin W. Vogtle } 1 \\
\text { (PWR; } 1,150 \mathrm{MWe})\end{array}$ & $\begin{array}{l}\text { Short-term SBO event: A truck carrying fuel oil hit a } 230 \mathrm{kV} \text { power line pole near the } \\
\text { switching station while the reactor was shut down. The power line was grounded during } \\
\text { the inspection of EDGs. The unit tripped immediately after the remaining EDG (1A) } \\
\text { was activated. It began operating after the third attempt. The SBO lasted for } 36 \text { minutes. } \\
\text { The temperature of the primary circuit increased from } 36^{\circ} \mathrm{C} \text { to } 60^{\circ} \mathrm{C} \text {. A site emergency } \\
\text { was announced. Cause: Defective temperature sensor led to failed EDG startup. }\end{array}$ \\
\hline March 21, 1991 & $\begin{array}{l}\text { Zion } 2 \\
\text { (PWR; 1,040 MWe) }\end{array}$ & $\begin{array}{l}\text { Near SBO event: A deluge valve was opened by mistake during a surveillance test of } \\
\text { the fire water system for the reactor in operation. A large amount of spray water caused } \\
\text { the tripping of a generator. One EDG was being serviced, so it was not available for use. } \\
\text { The power supply was restored in } 60 \text { minutes by using an off-site source. }\end{array}$ \\
\hline August 24, 1992 & $\begin{array}{l}\text { Turkey Point } 3 \text { and } 4 \\
\text { (PWR; } 700 \mathrm{MWe})\end{array}$ & $\begin{array}{l}\text { Near SBO event: Five EDGs became inoperative when the switchgear connecting them } \\
\text { to a safety system became wet during a hurricane that lasted for } 6 \text { and half days. The } \\
\text { plant was remodeled in accordance with the SBO regulations. }\end{array}$ \\
\hline February 6, 1996 & $\begin{array}{l}\text { Catawba } 2 \\
\text { (PWR; } 1,130 \text { MWe) }\end{array}$ & $\begin{array}{l}\text { Near SBO event: The loop was stopped for } 330 \text { minutes due to inadequate insulation. } \\
\text { One of the two EDGs became operative after the battery charger had been repaired. } \\
\text { However, the recovery was delayed by an improper procedure. }\end{array}$ \\
\hline June 2, 1998 & $\begin{array}{l}\text { Davis-Besse } \\
\text { (PWR; } 910 \mathrm{MWe})\end{array}$ & $\begin{array}{l}\text { Near SBO event: A tornado damaged the power supply equipment and one EDG failed } \\
\text { to operate. }\end{array}$ \\
\hline
\end{tabular}

impossible to achieve. In 1978, the regulatory authority SCSIN requested installation modifications to reduce risks and the development of procedures to cope with severe accidents. It also requested measures for SBOs by revising the basic safety rules (1985) and quoting guidelines $(1983)^{4}$. By 1989, the installation of sand bed filtered containment venting systems had been completed in all power plants. Moreover, the aforementioned functional loss of a safety system caused by flooding at the Blayais Nuclear Power Plant prompted Électricité de France (EDF) to prolong the duration of SBOs in its scenarios from 1 day to 3 days and conduct the evaluation again to reinforce measures against flooding (e.g., tide embankments and various equipment) ${ }^{2)}$.

Regulatory authorities in the United States and France are clearly taking measures against severe accidents by establishing requirements for dealing with long-term SBOs based on the many findings that they have gained.

\section{Regulation of Severe Accidents in Japan}

Studies of severe accidents have been conducted since the establishment of the Severe Accident Research Laboratory in the former Japan Atomic Energy Research Institute (JAERI) in 1984, which was prompted by the accident that occurred at TMI-2 in March 1979. However, this laboratory was merged into Thermal Hydraulic Safety Research Laboratory as early as 2001.

Discussions on measures against severe accidents began in 1987, almost 8 years after the TMI-2 Accident. These discussions were conducted by the Council on Common Issues set up by the Expert Committee on Reactor Safety Standards under the Nuclear Safety Commission 
(NSC).

Subsequently, the former Regulatory Guide for Reviewing the Safety Design of Nuclear Power Reactor Facilities, which had been established in 1977, was revised in August 1991. Guideline 27 ("Design consideration against the loss of power supplies") of this guide requires reactor facilities to be designed to ensure that they shut down safely and that the reactors are then cooled properly in the event of any short-term total loss of AC power supplies (SBO). Guideline 27 simply carries over the provisions of Guideline 9 from the former guide without revision. The commentary for Guideline 27 provides the following explanation: "Long-term total loss of AC power supplies need not be considered because the power lines can be restored or the emergency AC power supply equipment can be repaired. The design does not need to anticipate a total loss of AC power supplies if the emergency AC power supply equipment is highly reliable either in its configuration or operation (e.g., constantly kept operational)." At present, the Subcommittee on the Regulatory Guide for Reviewing the Safety Design of Nuclear Power Reactor Facilities is discussing a revision of Guideline 27. According to their documentation, consideration of long-term SBOs was formerly deemed unnecessary while the design was required to "ensure the safe shutdown and subsequent cooling of reactors in the event of a short-term SBO (at least 30 minutes)."

In May 1992, the abovementioned Council recommended measures to prevent severe accidents and mitigate their impact in its report entitled "Management of Severe Accidents at Commercial Light-water Reactors." The Council strongly recommended that utilities voluntarily implement measures against severe accidents.

The NSC set up a working group on station blackouts under the Review Panel on the Analysis and Evaluation of Accidents and Failures at Nuclear Facilities. On June 11, 1993, the group issued a report on station blackouts at nuclear power plants ${ }^{4}$. This report describes short-term SBO events and the like in the United States and other countries and explains its judgment that the probability of an SBO occurring in Japan is lower owing to its reliable power supply systems. The escalation of an SBO to a severe emergency is considered very unlikely because external power supplies can be quickly restored. At the same time, the report points out the following key facts and observations.

- The United States and France have imposed regulatory requirements against long-term SBOs.

- Training must be conducted to enhance safety with respect to SBOs and ensure that operators remain familiar with the requisite procedures.

- New findings must be properly incorporated into the design, operation, maintenance management, and procedure manuals.

- Specific probabilistic safety assessments (PSA) must be conducted at each plant to estimate the core damage frequency due to SBOs and implement accident management measures.

These comments were completely forgotten, and nothing was done about them to prevent the Fukushima Daiichi disaster.

In October 1994, government ministries and agencies submitted a report on the results of their discussions on measures against severe accidents. Having received this report, the NSC examined the validity of the relevant measures in the newly established Comprehensive Investigation Committee on Reactor Safety. The validated results were issued in December 1995 (White Paper on Nuclear Safety, 1995).

Less number of reports regarding severe accidents in Japan have almost certainly been published by researchers since 1995, but the author has been unable to identify any reports on the relevant regulations.

Japanese regulations do not reflect any of the relevant regulations developed in the United 
States and France or any of the knowledge gained in those countries. Regrettably, Japan did not go any further than the recommendations made by researchers for the clear regulation of severe accidents.

Reports such as those mentioned earlier are worthless if the information that they provide is shelved without any follow-up. The need for a regulatory system that carefully selects and applies the relevant information to regulations is being keenly felt.

\section{Reason for the Failure to Apply Knowledge of the Major Tsunami Discussed in the Interim Reports on Seismic Assessments by TEPCO}

An article published in the April 2011 issue of Nikkei Business (a major weekly magazine in Japan) mentioned that TEPCO had been aware of the possibility that a large tsunami could occur. This surprising fact prompted the author to investigate the reason why such knowledge had not been leveraged.

As mentioned above, the Nuclear Safety Commission issued a major revision to the Regulatory Guide for Reviewing the Seismic Design of Nuclear Power Reactor Facilities on September 19, 2006, and the following describes the situation that prevailed thereafter.

The Nuclear and Industrial Safety Agency (NISA) submitted a written request (Nuclear and Industrial Safety Agency Issue No. 6, dated September 19, 2006) for nuclear power utilities to investigate and evaluate seismic safety (including tsunami measures). In response, Tokyo Electric Power Company (TEPCO) submitted the following interim reports to NISA in March 2009.

- Joint Report W32-2-1: "Interim Report on an Evaluation of the Seismic Safety of Unit 5 at TEPCO's Fukushima Daiichi Nuclear Power Plant Following the Adoption of the Revised Regulatory Guide for Reviewing the Seismic Design of Nuclear Power Reactor Facilities"

- Joint Report W32-2-2: "Interim Report on an Evaluation of the Seismic Safety of Unit 4 at TEPCO's Fukushima Daini Nuclear Power Plant Following the Adoption of the Revised Regulatory Guide for Reviewing the Seismic Design of Nuclear Power Reactor Facilities".

In response to the above interim reports, the Joint Working Group on Earthquake, Tsunami, Geology, and Ground Foundation (under the Seismic and Structural Design Subcommittee, Nuclear and Industrial Safety Subcommittee, Advisory Committee for Natural Resources and Energy) held the following notable discussion on June 24, 2009.

An expert member of the working group began the discussion by saying, "In 869, Japan was struck by the extremely large Jogan Tsunami. Why did the report not mention this tsuna$\mathrm{mi}$ at all despite the availability of investigation findings on it?"

TEPCO replied by saying, "There was not much sign of damage. Although we consider this tsunami to be a topic for research, a representative example of an earthquake that should be taken into account in seismic designs is the Shioyazaki-oki Earthquake (1938; M 7.5; estimated height: $5.7 \mathrm{~m}$ )." In response to TEPCO's comment, a member of the working group pointed out that the Jogan Earthquake was estimated to have had a magnitude of around 8.5 based on the model developed by the National Institute of Advanced Industrial Science and Technology (AIST). For the Jogan Tsunami, it estimated that over 1,000 people died, as recorded in the Nihon Sandai Jitsuroku (an historical record of ancient Japan). The method used by the AIST, which involves estimating the time of an earthquake based on analysis of sand 
and other sediment that have been carried inland, is adopted by the Japanese Government's Central Disaster Prevention Council. The NISA Secretariat managed to smooth things over for the time being by saying, "The Jogan Tsunami shall be taken into account in the final report" as the AIST and Tohoku University have knowledge about this tsunami (Summary based on the meeting minutes and other relevant sources of information).

A bulletin published by Gakushikai (an alumni community of major Japanese universities) explains the Jogan Tsunami as follows ${ }^{7)}$ : "The earthquake is estimated to have had a magnitude of 8.4 or more, and the area of distribution for the deposits caused by the Jogan Tsunami that followed is almost the same as the area inundated by the tsunami that followed the Great East Japan Earthquake in March 2011. Going forward, we will report the results of our detailed investigation."

The above opinion was, however, put to one side and omitted in the interim reports. On July 21, 2009, the NISA commission validated these reports. In addition, the NSC endorsed the views presented in these reports. There is no record of the NSC having discussed this issue with respect to the same earthquake.

On August 25, 2011, the Asahi Shimbun (a major newspaper in Japan) essentially reported that "according to an evaluation conducted in 2002 by the Headquarters for Earthquake Research Promotion of the Japanese government, TEPCO estimated that an earthquake off the coast of Boso with a postulated magnitude of M 8.3 would direct a tsunami wave with a height of $10.2 \mathrm{~m}$ toward Units 5, 6 and another with a height of between 8.4 and $9.3 \mathrm{~m}$ toward Units 1 to 4. This finding was reported to TEPCO's upper management in June 2008. In September 2009, TEPCO orally informed NISA personnel of the possibility of a tsunami with a height exceeding $6 \mathrm{~m}$, but NISA did not provide any special instructions. Moreover, 4 days before the earthquake, TEPCO reported the risk of a tsunami with a height exceeding $10 \mathrm{~m}$ to NISA." On October 3, NHK disclosed the report requested from NISA. It is extremely regrettable to find that, despite the findings and actions described above and the fact that the high risk of a tsunami had already been identified in an estimate produced by the Japan Nuclear Energy Safety Organization (JNES), a serious accident occurred due to a failure to implement appropriate measures. An investigation must be conducted to determine whether NISA passed this information on to the Nuclear Safety Commission to be properly double-checked. Poor communication between the JNES, which had essential knowledge, and NISA, as the executive branch for regulation, has already been identified.

Furthermore, it is debatable whether there is truly no need to implement guidelines for protective measures against tsunamis for Japanese plants located along the coast, especially when the United States has put in place RG 1.102 "Flood Protection for Nuclear Power Plants" and RG 1.59 "Design Basis Floods for Nuclear Power Plants."

\section{Conclusions}

In hindsight, it is clear that useful information could have been provided concerning proper measures against tsunamis in Iwate, Miyagi, Fukushima, Ibaraki, and other prefectures if the nuclear communities had begun discussions on findings related to earthquakes and tsunamis in 2009 at the latest, and had opened for public.

Clear regulatory requirements for measures against severe accidents must be introduced in place of the voluntary safety measures currently adopted by utilities. In particular, efforts to learn from SBO and near SBO events must be required to ensure that proper training is conducted. Human resource must be developed to cultivate broad views and keep track of 
findings from studies on SBOs around the world as well as information on topics such as reactor safety systems, earthquakes, tsunamis, structures, and regulations.

The author sincerely hopes that the nuclear power utilities will go back to basics and re-evaluate their technologies, actively engage in the development of technologies to ensure safety, and enhance their site management to disseminate clear and adequate information from the site.

As of the time of writing, the media is reporting on the possibility of integrating NISA and the NSC into the Nuclear Safety Agency to address the inadequate regulatory system in place today. The obsession with details that prevails under the current regulations is an obstacle to transitioning to risk-oriented regulations and the proper adoption of lessons learned from the practices, accidents, and troubles experienced in other countries. Moreover, a transition from emphasizing inspections of structural strength to conducting inspections of system functions has yet to be made. The Reactor Regulation Act still needs to be unified with the Electricity Business $\mathrm{Act}^{8}{ }^{8}$. The regulations have not adequately addressed the issues that were identified in the Integrated Regulatory Review Service conducted by the IAEA in $2008^{9 \text { ). }}$

In recognition of these lessons learned, active discussions must be facilitated by adopting the latest findings in order to build a transparent regulatory system.

In closing, it is worth mentioning that the Nuclear Safety Division of the Ibaraki Prefectural Government noticed and reported that the level of flooding at the Tokai Daini Nuclear Power Plant indicated by the tsunami disaster prevention map was higher than that postulated in the design. This led to a valuable experience that subsequent discussions among stakeholders prompted the implementation of various measures based on the information provided in the map and ensured the operation of cooling pumps at the plant.

\section{References}

1) Safety-related Backup System Failure Due to Flooding at the Blayais Nuclear Power Plant in France [in Japanese], Nucleonics Week (Japanese Edition), 2000.1.6.

2) J. M. Mattei, E. Vial, V. Rebour, H. Liemersdorf, and M. Turschmann: Generic Results and Conclusions of Re-evaluating the Flooding in French and German Nuclear Power Plants, Eurosafe Forum 2001, published 2001.

3) Safe Shutdown of Kalpakkam 2 in India Prompted by the Infiltration of Seawater into the Pump House, INES Case No. 0802-00.

4) Station Blackouts at Nuclear Power Plants [in Japanese], Working Group on Station Blackouts, Review Panel on the Analysis and Evaluation of Accidents and Failures at Nuclear Facilities, June 11, 1993.

5) Regulatory Effectiveness of the Station Blackout Rule, NUREG-1776, August 2003.

6) Analysis of Long-Term Station Blackout Automatic Depressurization at Peach Bottom Using MELCOR (Version 1.8), NUREG/CR-5850, May 1994.

7) Y. Okamura: Prediction of Massive Earthquakes and Tsunamis [in Japanese], Gakushikai Kaihou No. 890 (2011-V).

8) Y. Nishiwaki: Issues and Discussions on the Regulation of Nuclear Power Plants [in Japanese], Journal of the Atomic Energy Society of Japan, 51 (8), 616 (2009).

9) IAEA: Integrated Regulatory Review Service (IRRS) to Japan, (6/2008). 